\title{
Evidence for autosomal recessive inheritance in cerebral gigantism
}

\author{
S. NEVO,* M. ZELTZER, † A. BENDERLY, $†$ and J. LEVY†
}

\begin{abstract}
Summary. Three cases of cerebral gigantism, two sibs and their double first cousin, are described in a large inbred family from Israel. Two of the three were observed and diagnosed at birth and two were followed for two years. They all presented the signs and symptoms considered typical of this syndrome, as well as some of the less frequent findings. Generalized oedema and flexion contractures of the feet were observed in two of the three at birth. This has not hitherto been reported in cases of cerebral gigantism, of whom only a few have been observed and diagnosed at birth. Autosomal recessive inheritance is clearly implied in this family.
\end{abstract}

The syndrome of cerebral gigantism was first described by Sotos et al in 1964. Its main features include accelerated linear growth and skeletal maturation, acromegaloid features with craniofacial peculiarities, and a nonprogressive neurological disorder with mild mental retardation. The neurological findings and the mental retardation are usually ascribed to various degrees of cerebral atrophy, since communicating hydrocephalus was found in most cases where a pneumoencephalography was performed. In contrast to their accelerated physical growth, affected children lag in their psychomotor development. Eighty cases have been reported and reviewed by Jaeken, Van Der Schueren-Lodeweyekx, and Eeckels in 1972. The most frequently documented craniofacial abnormalities were: dolichocephaly, frontal bossing, a high arched palate, prognathism, and an antimongoloid slant. Other frequently recurring findings include generalized muscular hypothonia, clumsiness, a peculiar gait, and skeletal anomalies such as kyphosis, kyphoscoliosis, and limb abnormalities.

Cerebral gigantism is classified in the group of diencephalic syndromes of infancy, all of which present a disturbance in growth regulation. However, unlike other diencephalic syndromes, no anatomical lesion in the diencephalon or a specific

\footnotetext{
Received 28 September 1973.

* Human Genetic Laboratory, Department of Biology, The University of Haifa, Haifa, Israel.

t Rambam Government Hospital, Haifa, Israel.
}

biochemical abnormality are known to account for this syndrome.

Familial occurrence of cerebral gigantism was first reported by Hook and Reynolds in 1967, in an affected pair of monozygotic twins. There are also reports of affected first cousins (Schotte, 1967) and a baby whose elder brother was mildly affected (Bejar et al, 1970).

The possibility of genetic determination has been discussed by several authors. However, the available supportive evidence was insufficient and was considered inconclusive. This presentation deals with a report of three cases in two related sibships of a large inbred family from Israel. The affected cases present with the cardinal signs and symptoms of cerebral gigantism and some additional features previously undescribed. The family pattern leaves little doubt regarding the role of genetics in this particular case.

\section{Case Reports}

\section{Sibship I}

Case 1, V.5. The propositus, a male, was born at term after a normal pregnancy, to a 28 -year-old mother and a 38-year-old father. Birth weight and body measurements are shown in Table I. Examination at birth revealed severe oedema of the eyelids, hands, and feet with dorsiflexion contractures of the oedematous feet, a marked generalized muscular hypotonia, a prominent forehead, large low-set and malformed ears, a narrow high arched palate, a conspicuous lumbosacral kyphosis, an umbilical hernia, and bilateral undescended testes. 
TABLE I

ANTHROPOMETRIC DATA

\begin{tabular}{|c|c|c|c|c|c|c|c|c|}
\hline & Age & Weight (g) & Length $(\mathrm{cm})$ & Percentile & $\underset{(\mathrm{cm})}{\text { Head }} \underset{\text { Circumference }}{ }$ & Length Age & Bone Age* & Remarks \\
\hline Case 1 & $\begin{array}{l}\text { Birth } \\
\\
6 \text { months } \\
14 \text { months }\end{array}$ & $\begin{array}{r}3200 \\
8300 \\
11,600\end{array}$ & $\begin{array}{l}62 \\
\\
78 \\
78 \\
86\end{array}$ & $\begin{array}{l}>97 \\
\\
>97 \\
>97\end{array}$ & $\begin{array}{l}36 \\
\\
43 \\
47\end{array}$ & $\begin{array}{l}\text { 3-4 months } \\
15 \text { months } \\
23 \text { months }\end{array}$ & 6 months & $\begin{array}{l}\text { Determined by } \\
\text { occurrence of } \\
\text { ossification centres } \\
\text { in heads of femur }\end{array}$ \\
\hline Case 2 & 6 years & 22,100 & 128 & $>97$ & 48 & $8 \frac{2}{13}$ years & & \\
\hline Case 3 & Birth & 3400 & 58 & $>97$ & 37 & 2 months & 6 months & $\begin{array}{l}\text { Ossification centres } \\
\text { in heads of femur }\end{array}$ \\
\hline
\end{tabular}

* Determined according to Greulich and Pyle (1959).

There was a bilateral wrist-drop with spindle shaped fingers, bilateral clinodactyly, and a bilateral simian crease (Figs. 1 and 2). Breathing, heart sounds, liver, and spleen size were all normal as was radiology of the skull, hands, and wrist bones which showed a normal bone age for a newborn. Radiology of the hip joints, for a suspected subluxation, revealed ossification centres in

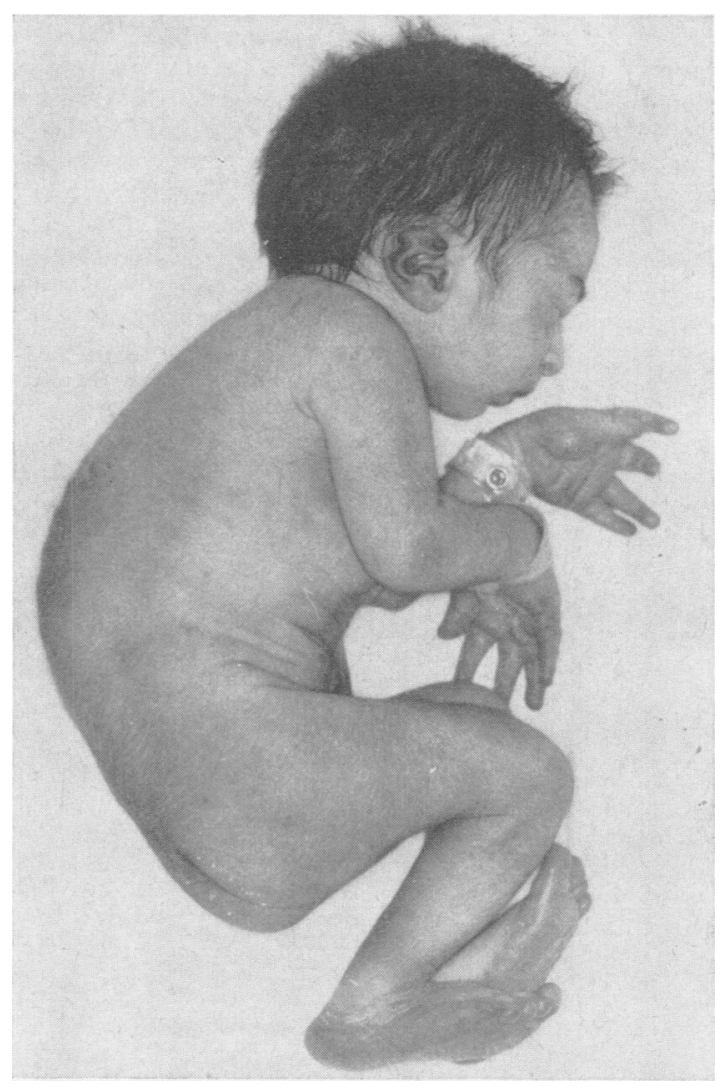

FIG. 1. Case 1 (V.5), at birth. the heads of the femur bones, usually observed at 2 to 10 months of age. A neonatal jaundice of $20 \mathrm{mg} \%$ bilirubin had developed and subsided gradually with no known cause revealed in examinations. The baby was discharged and readmitted for detailed examinations at the age of 6 months. At that time he was well nourished, good tempered, and gave the impression of an alert baby with normal intelligence for his age (Fig. 3). Anthropometric data are shown in Table I. The oedema had disappeared but the generalized muscular hypotonia and the dorsiflexion contractures of the feet remained. His movements were very clumsy and he could not raise his head or roll over. Dolichocephaly and acromegaloid features became obvious. Response to auditory and visual stimuli were normal. Fundoscopy revealed normal optic discs with increased central reflex of the retinal artery origin and fine tesselation scattered bilaterally. Tendon reflexes were sluggish and the Babinsky reflex was positive bilaterally. EEG was normal. EMG did not indicate muscular or peripheral nerve damage. Light and electron microscopy of muscle biopsy showed no structural changes. ECG was normal. Routine laboratory examinations included; urinalysis, CBS, VDRL, blood urea, glucose, total protein,

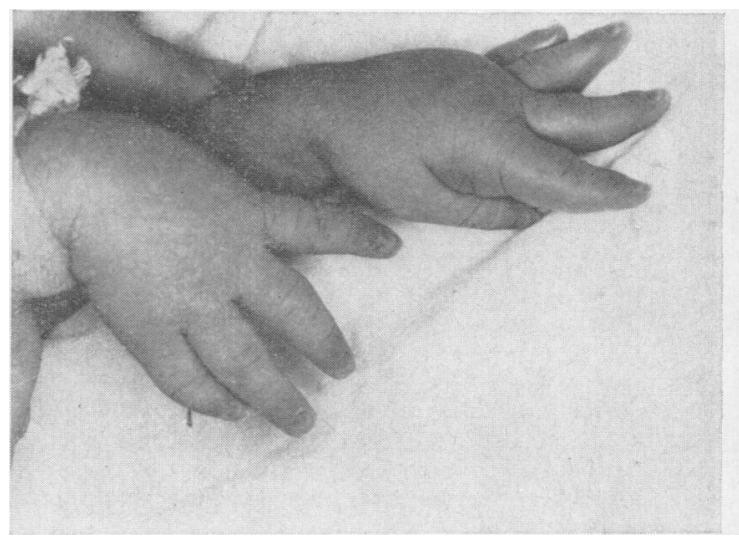

FIG. 2. Case 1 (V.5) at birth. Note severe oedema of hands with spindle shaped fingers and wrist-drop. 


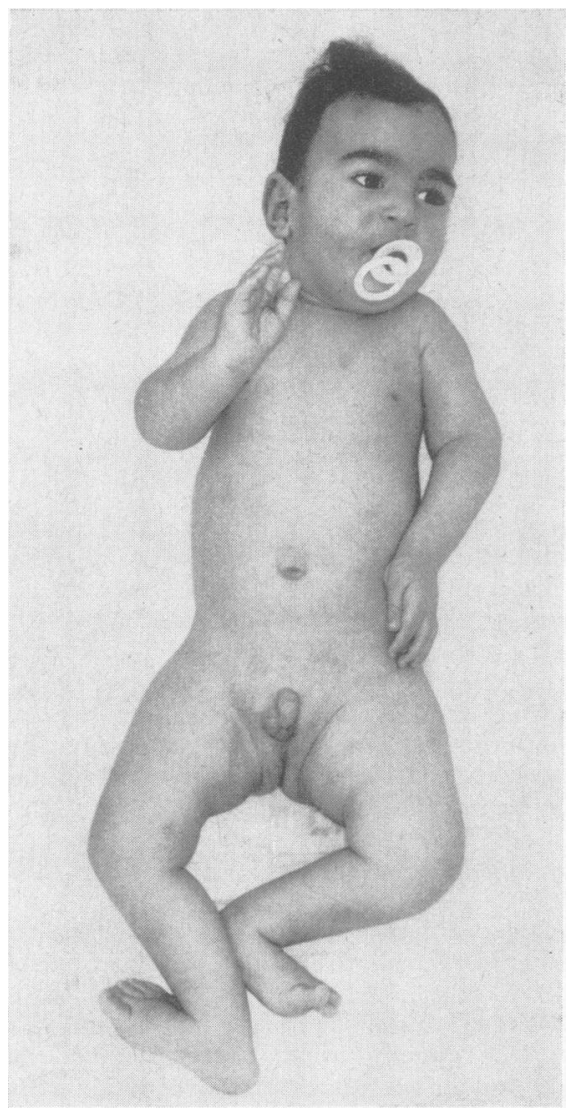

Fig. 3. Case 1 (V.5) at six months.

albumin, globulin, alkaline phosphatase, acid phosphatase, uric acid, creatinine, $\mathrm{Cl}, \mathrm{Na}, \mathrm{K}, \mathrm{CO}_{2}, \mathrm{P}$, serum iron, cholesterol, and SGOT; all these were within the normal range.

Blood was also examined for pheylalanine, tyrosine, lactic dehydrogenase, phosphocreatine kinase, aldolase 1 , 6 diphosphate, and aldolase 1 phosphate. All were with- in the normal range except for an elevation of lactic dehydrogenase to 295 units (normal range 83-185 units). There was no aminoaciduria. Radiological examinations revealed a normal skull, slight skoliosis, and a severe dorsolumbar kyphosis, anteversion of hip joints with normally developed joints, femurs in varus position, and an ulnar deviation of the hands. The boy was readmitted to the hospital for metabolic studies at the age of 14 months. He was in very good general health. At that time he was able to sit and stand up when holding onto something. Again, the impression was of an alert intelligent boy, interested in his environment (body measurements are shown in Table I). A series of endocrinological tests were done with the following results: PBI was normal and urinary 24 hour excretion of 17-ketosteroids and 17-hydrocorticosteroids were within the normal range. Adrenal response to metyrapone administration was normal; there was a four-fold rise of $170 \mathrm{H}$ corticosteroid excretion in a 24-hour urine collection. Growth hormone response in an insulin tolerance test was normal showing a rise from $8.4 \mu \mathrm{g} / \mathrm{ml}$. to 23 $\mathrm{m} \mu \mathrm{g} / \mathrm{ml}$. in 60 minutes. In an oral glucose tolerance test there was a normal suppression of $\mathrm{GH}$ from 12.5 $\mathrm{m} \mu \mathrm{g} / \mathrm{ml}$ at time zero to $1.5 \mathrm{~m} \mu \mathrm{g} / \mathrm{ml}$ at 30 minutes and a return to a level of $12 \mathrm{~m} \mu \mathrm{g} / \mathrm{ml}$ at 5 hours. Administration of the glucose in this test caused a brisk rise of plasma insulin level from $10 \mathrm{~m} \mu \mathrm{g}$ to $70 \mathrm{~m} \mu \mathrm{g}$ within 45 minutes. The results were interpreted as normal. Concentration of amino acids in plasma were normal. Chromosome culture from peripheral lymphocytes revealed a normal male karyotype. Dermatoglyphic analysis is shown in Table II.

Case 2, V.3. Repeated enquiry into the family history revealed a similarly affected elder sister. She was $5 \frac{1}{2}$ years old when her affected brother was born. No medical records reporting her previous development were available. Information from her parents disclosed that she was 'long at birth', weighed $3800 \mathrm{~g}$ and had a severe neonatal jaundice; that her muscles were very weak and her head 'always dropped'. She sat at the age of 1 year but never stood or walked on her own, and first spoke at the age of 2 years. When first seen, at the age of 6 years she looked very long for her age, had a severe dorsolumbar kyphosis, and was dolichocephalic with acromegaloid features (Figs. 4 and 5). Her forehead was

TABLE II

DERMATOGLYPHICS OF TWO CASES AND THEIR PARENTS

\begin{tabular}{|c|c|c|c|c|c|c|c|c|c|c|c|c|c|c|c|c|c|}
\hline \multirow{3}{*}{ Case } & \multicolumn{10}{|c|}{ Finger-tip Pattern Types } & \multirow{3}{*}{ TRC } & \multirow{3}{*}{$\begin{array}{c}\text { A-B } \\
\text { count }\end{array}$} & \multirow{3}{*}{$\underset{\text { atd }}{\text { Maximal }}$} & \multirow{2}{*}{\multicolumn{2}{|c|}{ C Triradius }} & \multirow{2}{*}{\multicolumn{2}{|c|}{$\begin{array}{l}\text { A-line } \\
\text { Exists }\end{array}$}} \\
\hline & \multicolumn{5}{|c|}{$\mathbf{L}$} & \multicolumn{5}{|c|}{$\mathbf{R}$} & & & & & & & \\
\hline & 5 & 4 & 3 & 2 & 1 & 1 & 2 & 3 & 4 & 5 & & & & $\mathbf{L}$ & $\mathbf{R}$ & $\mathbf{L}$ & $\mathbf{R}$ \\
\hline $\begin{array}{l}\text { V.3 } \\
\text { V.5 } \\
\text { IV.4 } \\
\text { IV.7 }\end{array}$ & $\begin{array}{l}\mathbf{U L} \\
\mathbf{U L} \\
\mathbf{U L} \\
\mathbf{U L}\end{array}$ & $\mid \begin{array}{l}\mathbf{U L} \\
\mathbf{W} \\
\mathbf{W} \\
\mathbf{W}\end{array}$ & $\begin{array}{l}\mathbf{U L} \\
\mathbf{W} \\
\mathbf{U L}\end{array}$ & $\underset{\mathbf{W}}{\mathbf{U L}}$ & $\mid \begin{array}{l}\mathbf{W} \\
\mathbf{W} \\
\mathbf{U L} \\
\mathbf{W}\end{array}$ & $\begin{array}{c}\mathbb{W} \\
\mathbb{W} \\
\mathbf{W}\end{array}$ & $\underset{\mathbb{W}}{\mathbf{U}}$ & $\left|\begin{array}{l}\mathbf{U L} \\
\mathbf{W} \\
\mathbf{W}\end{array}\right|$ & $\begin{array}{l}\mathbb{W} \\
\mathbb{W} \\
\mathbf{W}\end{array}$ & $\begin{array}{l}\mathbf{U L} \\
\mathbf{W} \\
\mathbf{W} \\
\mathbf{W}\end{array}$ & $\begin{array}{l}179 \\
239 \\
164 \\
175\end{array}$ & $\begin{array}{l}80 \\
79 \\
74 \\
72\end{array}$ & $\begin{array}{l}70 \cdot 5 \\
89 \\
78 \\
82\end{array}$ & $\begin{array}{l}\text { Absent } \\
\text { Absent } \\
\text { Present } \\
\text { Present }\end{array}$ & $\begin{array}{l}\text { Absent } \\
\text { Absent } \\
\text { Absent } \\
\text { Present }\end{array}$ & $\begin{array}{l}3 \\
2 \\
4 \\
4\end{array}$ & $\begin{array}{l}4 \\
3 \\
4 \\
4\end{array}$ \\
\hline \multicolumn{11}{|c|}{$\begin{array}{l}\text { Normal population values } \\
\text { Males } \\
\text { Females }\end{array}$} & $\begin{array}{l}145 \\
127\end{array}$ & $\begin{array}{l}81.9 \\
83.0\end{array}$ & & & & & \\
\hline
\end{tabular}




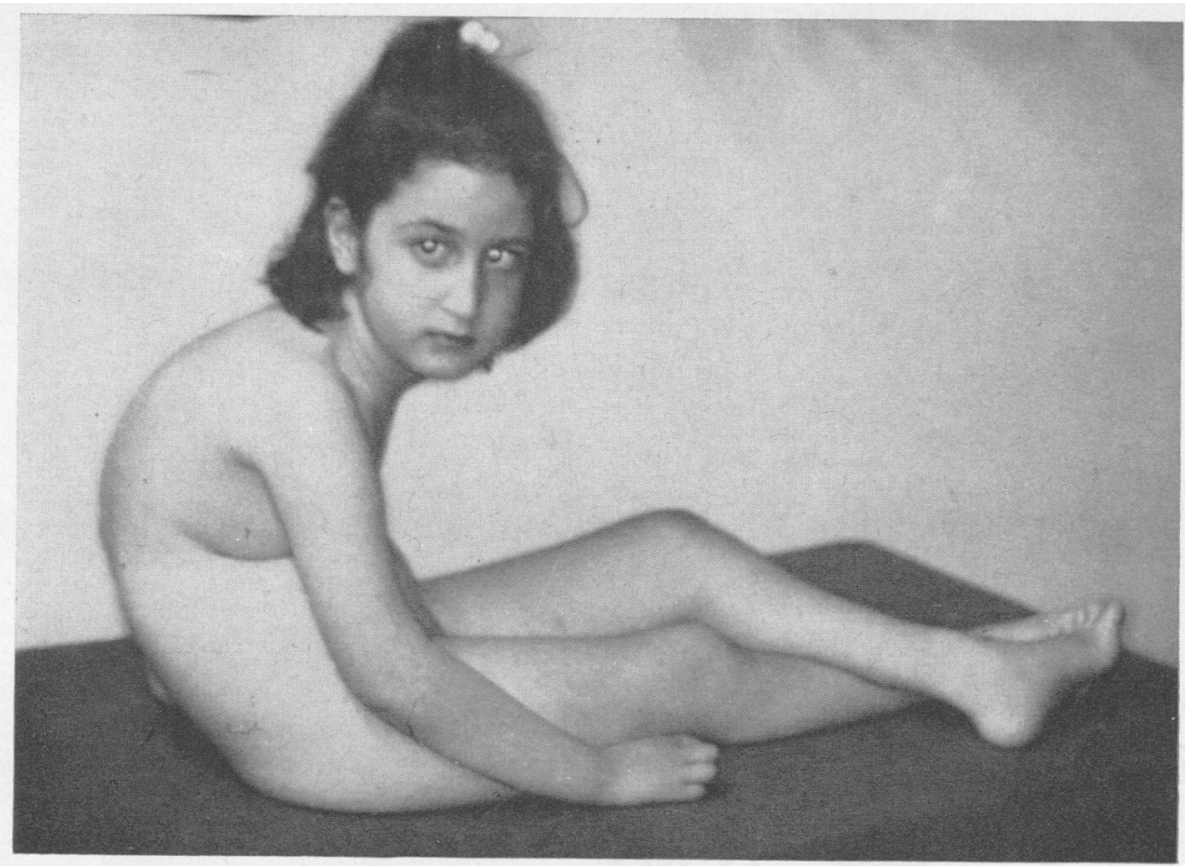

prominent with frontal bossing. She had a bilateral convergent squint, a slightly antimongoloid slant, hypertelorism, a high arched palate, a large lower mandible, and large low-set ears. She was definitely mentally retarded and had a very strange voice. There was hirsutism and a severe general muscular hypotonia with very clumsy movements. She also had a bilateral pes planovalgus and prominent calcanei. Examination of the chest and abdomen, response to auditory and visual stimuli, and fundoscopy were all normal. Responses of tendon reflexes were sluggish with a positive Babinsky reflex on the right and weakness of the VIth cranial nerves. EEG recorded a slow rhythm over the posterior region on the right. EMG did not indicate muscular or peripheral nerve damage and examination of muscle biopsy material did not show structural changes. She was submitted to the same urine and blood tests as her brother, with the same normal results, except for a slight elevation in serum lactic dehydrogenase also detected in her brother's serum (203 units as compared to a normal range of 83-185 units). No aminoaciduria was found. Radiological examinations revealed a relatively large skull with a small sella turcica, a dorsolumbar scoliosis with prominent kyphosis of the lower dorsal and upper lumbar spine, wedge-shaped lower dorsal and upper lumbar vertebrae, both femurs in anterversion, osteoporosis of the spine, arm and leg bones, and a normal IVP. She was not submitted to a full endocrinological examination because of her parents' objection. PBI and excretion of 17 ketosteroids and 17 hydroxy- corticosteroids were normal. Plasma amino-acid concentrations were normal. Peripheral lymphocyte culture revealed a normal female karyotype. Results of dermatoglyphic studies are in Table II.

\section{Sibship II}

Case 3, V.9. A male infant, double first cousin of the propositus, was born three months after his cousin to a healthy 30-year-old mother and a 40-year-old father. His three elder sibs were healthy and of average height. His pregnancy and delivery were normal. His striking resemblance at birth to the propositus is shown in Figs. 6 and 7. Body measurements at birth are shown in Table I. Like the propositus he was born edematous with severe flexion contractures of the feet and very similar hands (see Figs. 6 and 7). His ears were also large, malformed, and low set, he had a high arched palate, severe dorsolumbar kyphosis, generalized muscle hyptonia, bilateral wrist-drop, bilateral talipes calcaneus, lack of patellar reflexes, and bilateral undescended testes. He developed a severe neonatal jaundice of $19 \mathrm{mg} \%$ bilirubin which gradually subsided. Radiology of the skull was normal but radiology of the pelvis and hip joints revealed ossification centres in the heads of the femur on both sides. He had a normal male karyotype. At two weeks he had developed a severe bacterial pneumonia which led to his death at 33 days of age. At 30 days, with a bulging anterior fontanelle, his head circumference grew from $37 \mathrm{~cm}$ at birth to $41 \mathrm{~cm}$, 


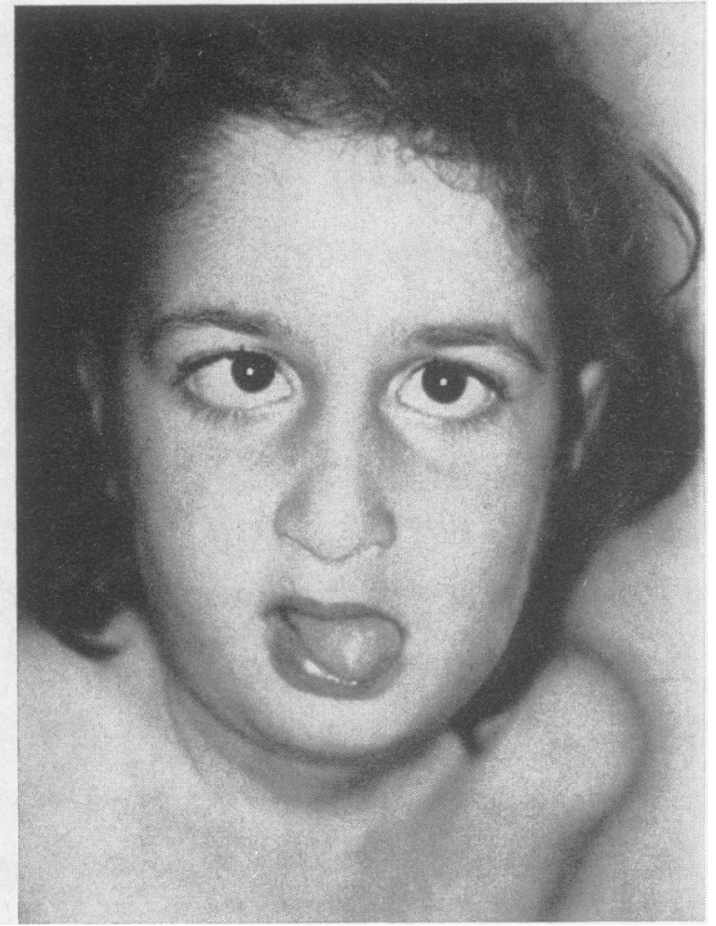

Fig. 5. Fạcial appearance of case 2 (V.3) at the age of 6 years.

indicating the development of hydrocephalus. A postmortem examination was not permitted by the family.

The Family (Fig. 6). The affected children were observed in two, very closely related sibships of a large Arab family from Israel. Recurrent consanguineous marriages are customary in many such families. Hence, the affected members of the two sibships are double first cousins while both parent couples are second cousins (Fig. 8). The coefficient of inbreeding calculated for the affected sibships is $F>0 \cdot 1352$. (The exact figure could not be calculated because the relationship between II.1 and II.2 was unknown to the informants.) In sibship I, the offspring of IV.4 and IV.7, there were two cases of intrauterine death and one infant death due to severe congenital cardiac anomalies. The only living non-affected boy in this sibship (V.2), has a low average height for his age, with very delicate facial features and, unlike his two affected sibs, resembles his parents very much. The mother's height is $161 \mathrm{~cm}$ and the father's $164 \mathrm{~cm}$. The parents (V.5 and IV.8) of case 3 are also of low average height and so are their three normal children. All the living members of this family, from generations III, IV, and V, were seen and none of them was exceptionally tall, or resembled the two affected sibs facially.



Fig. 6. Case 3 (V.9) double first cousin of case 1 at birth.

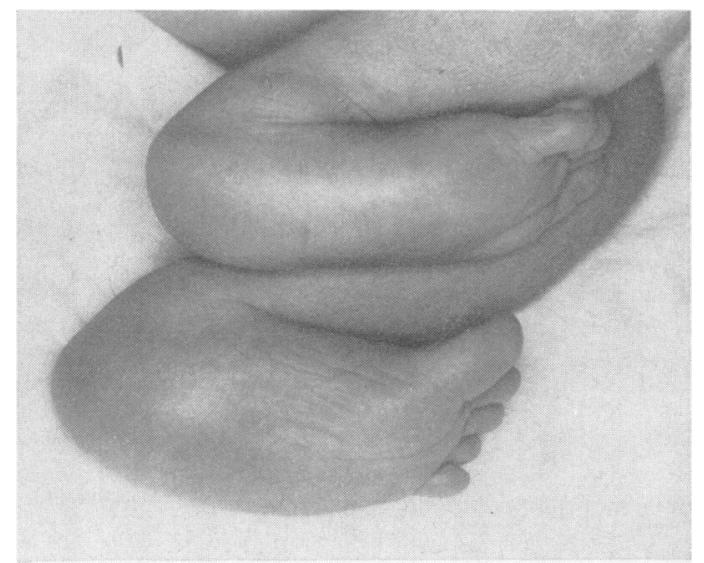

FIG. 7. Case $3(\mathrm{~V} .9)$ at birth. Note severe oedema and dorsiflexion contractures of feet. 


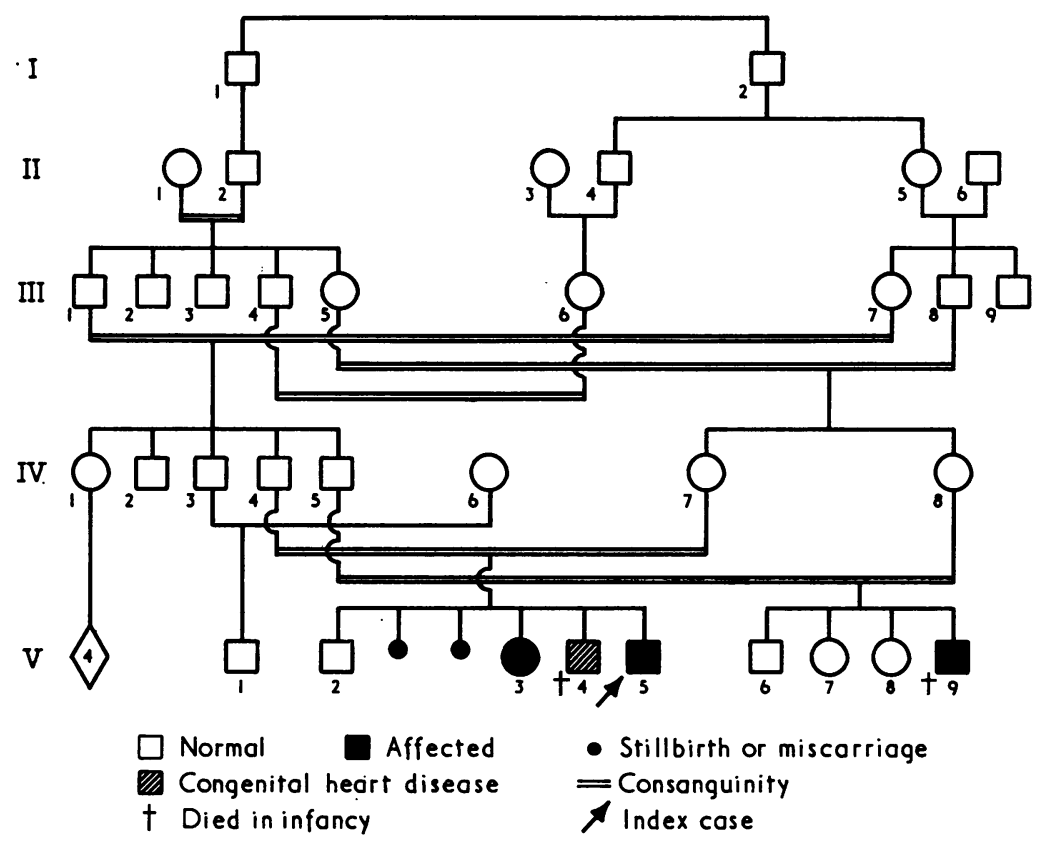

FIG. 8. Pedigree of the affected family.

\section{Discussion}

Discussion of the presented cases raises two major problems: the problem of diagnosis in cerebral gigantism and the role of genetics. Although we have seen only two of the three cases at birth, we believe they all present with the same congenital syndrome. The remarkable similarity of the two male infants at birth and the striking resemblance, developed by the propositus to his older affected sister, leave little doubt that this is so. Some anomalies, peculiar to our cases, have not as yet been reported in cerebral gigantism. These include the generalized oedema at birth, flexion contractures of the feet, wrist drop with clinodactyly, and the extreme muscular hypotonia at birth. Yet we believe that they all fulfil the major diagnostic criteria of cerebral gigantism. All three cases had accelerated intrauterine growth which continued in the surviving sibs V.3 and V.5. Whenever measured, body length was above the 97th centile (Table II). The advanced bone-age, similar to the height age rather than to the chronological age (Table 1), is known for most cases with cerebral gigantism (Sotos et al, 1964; Marie et al, 1965; Hook and Reynolds, 1967; Milunsky, Cowie, and Donoghue, 1967; Posnanski and Stephenson, 1967; Sizonenko et al, 1968; Jaeken et al, 1972). Dolichocephaly, large extremities, generalized mus- cular hypotonia, clumsiness, awkwardness, and retarded motor and speech development are considered typical. Our two surviving sibs have all these features. The most commonly observed skeletal anomalies in this disease-kyphosis or kyphoscoliosis (Sotos et al, 1964; Milunsky et al, 1967; Turner and Sloan, 1967; Gaudier et al, 1968; Ott and Robinson, 1969)-occur in the three cases as severe kyphoscoliosis. The unusual voice quality with a peculiar speech, present in V.3, was also described repeatedly (Cohen, 1964; Sotos et al, 1964; Hook and Reynolds, 1967; Milunsky et al, 1967; Turner and Sloan, 1967; Ott and Robinson, 1969). An unexplained severe neonatal jaundice, detected in our three cases, was reported in about $20 \%$ of the cases in the literature (Ott and Robinson, 1969). Dermatoglyphic abnormalities observed in several examined cases (Milunsky et al, 1967; Ott and Robinson, 1969; Bejar et al, 1970), included a high total ridge count and a vertical palmar alignment with a tenar exist of the $A$ line. A high A-B count was detected in two cases only. However, in most of the cases, no data were available for the parents. The two cases we have examined had a high total ridge count, particularly V.5 (Table II), but there is no vertical palmar alignment and the $A$ line exits are by no means thenar. 
Changes in concentration of certain amino acids, in plasma and muscle, were reported in two cases in 1970 by Bejar et al. In our two cases, V.3 and V.5, amino-acid concentrations in the plasma did not deviate significantly from concentrations in normal controls. However, of the plasma enzyme concentrations we have examined in the two cases, both showed an elevation of lactic dehydrogenase. Evaluation of this observation is impossible at present since levels of this enzyme in most previous cases were not reported. The possibility that this may recur in other cases is presently being looked into.

The differential diagnosis of cerebral gigantism includes a long list of syndromes of both endocrine metabolic and genetic aetiology. All these syndromes share the major finding of high stature and can be ruled out, as in our cases, by clinical findings and laboratory tests.

The main defect in cerebral gigantism is thought to be a disturbance in growth regulation, due either to an unknown abnormality in the diencephalonan abnormality in a growth factor other than the growth hormone-or to an abnormal response of peripheral tissues to stimulation by a normal level of growth hormone. The unknown metabolic defect is clearly expressed prenatally.

The finding of possible dermatoglyphic abnormalities, if substantiated, points to an expression at a very early embryonic stage. The argument for a genetic role in the aetiology of cerebral gigantism was based, mainly, on the finding of abnormal dermatoglyphics and the few familial case reports (Bejar et al, 1970). This argument was outweighed by the small proportion of familial, as compared to the bulk of sporadic cases in the literature. However, more careful enquiry into family histories has, in more recent publications, disclosed a few more cases with possible additional affected members in their families (Milunsky et al, 1967; Turner and Sloan, 1967; Sizonenko et al, 1968; Ott and Robinson, 1969; Bejar et al, 1970; Jaeken et al, 1972). Several factors contribute to a low ascertainment of multiple cases in such families. (1) The lack of a specific diagnostic test; (2) the variability in the clinical picture, with probable exclusion of those which are nearly normal in physical appearance, intelligence, and neurological examination. These can easily be considered as within the upper range of the normal curve for body size; (3) the fact that the abnormal growth is confined to early childhood (usually 0 to 4 years), makes a retrospective diagnosis impossible in an unknown proportion of cases; (4) the search for affected family members, whenever done, was mainly through taking family histories not through examination of all family members; (5) the mode of inheritance, suggested by our pedigree, which suits the few other affected families, offers a relatively low probability of finding multiple cases in small sibships. The skipping of generations in recessive syndromes reduces the chance of finding cases among first-degree relatives.

We believe that the difficulties mentioned above explain, to some extent, the small number of familial cases in the literature. Heredity, presumably autosomal recessive, was also questioned on grounds that no inbreeding was reported in any family of an affected offspring. In the earlier case reports, when genetics was not considered, it is doubtful whether inbreeding was enquired about routinely. More important may be the fact that the concentration of inbred families, in such a sample, is expected theoretically when the recessive gene is rare in the population. In view of the great variability in its expression, even in the homozygous form, and in the absence of a specific test for detection of milder cases, it is possible that this gene is not so rare.

The family history presented here clearly indicates genetic determination with autosomal recessive transmission. Clinical variability, in syndromes determined by a single gene, is usually ascribed to the modifying effects of the individual's genetic background and environmental factors. Why our three cases are clinically remarkably similar is understandable considering their similar genetic background in the highly inbred family. Although it is difficult to visualize how environmental factors can affect the phenotypic expression of this syndrome it may be worth noting that they also shared a very similar environment. It is customary, in such inbred families among Israeli Arabs, to build large houses which are shared by sibs with their mates, parents, and offspring. Housework and child care are performed as a joint effort of the women of the house for the whole household. Hence the children are exposed to the same habits, eat the same food, and share all other environmental factors. In such families both genetic and environmental modifying effects are in the same direction. To a smaller extent this is true for many other genetic syndromes, in other western families, where intra-familial variance in clinical picture is lower than the inter-familial variance. That we observed such a severe form of the syndrome in the three cases must be considered a chance effect, where originally a particular genetic set-up in an ancestor was perpetuated and duplicated through generations of inbreeding. 
We wish to thank Dr A. Szeinberg for the serum enzyme determinations, which were done in his laboratory and Mrs Dana Har-Even for examining the karyotypes and for the dermatoglyphic analysis.

\section{REFERENCES}

Bejar, R. L., Smith, G. F., Park, S., Spellacy, W. N., Wolfson, S. L., and Nyhan, W. L. (1970). Cerebral gigantism: concentrations of amino acids in plasma and muscle. Fournal of Pediatrics, 76, 105111.

Cohen, M. (1964). Cerebral gigantism in childhood. New England fournal of Medicine, 271, 635.

Gaudier, B., Ponté, C., Dehaene, P., Nuyts, J. P., and Ryckewaert, P. (1968). Encephalopathie infantile et dysmorphies complexes: III. le gigantisme cerebral. Lille Médical, 13, 760-765.

Greulich, W. and Pyle, S. I. (1959). Radiographic Atlas of Development of the Hand and Wrist. Stanford University Press, Palo Alto, California.

Hook, E. B. and Reynolds, J. W. (1967). Cerebral gigantism: endocrinological and clinical observations of six patients including a congenital giant, concordant monozygotic twins, and a child who achieved adult gigantic size. Fournal of Pediatrics, 70, 900-914.

Jaeken, J., Van Der Schueren-Lodeweyckx, M., and Eeckels, R (1972). Cerebral gigantism syndrome. A report of 4 cases and review of the literature. Zeitschrift für Kinderheilkunde, 112, 332-346.

Marie, J., Royer, P., Lévèque, B., Debauchez, C., and Rappaport, R. (1965). Gigantisme avec encéphalopathie et dysmorphie cranio-faciale. Annales de Pédiatrie, 41, 682-691.

Milunsky, A., Cowie, V. A., and Donoghue, E. C. (1967). Cerebral gigantism in childhood. A report of two cases and a review of the literature. Pediatrics, 40, 395-402.

Ott, J. E. and Robinson, A. (1969). Cerebral gigantism. American Journal of Diseases of Children, 117, 357-368.

Poznanski, A. K. and Stephenson, J. M. (1967). Radiographic findings in hypothalmic acceleration of growth associated with cerebral atrophy and mental retardation (cerebral gigantism). Radiology, 88, 446-456.

Schotte, H. (1967). Deux cas de gigantism cérébral. Acta Paediatrica Belgica, 21, 412-413.

Sizonenko, P. C., Job, J. C., Sebouk, S., and Rossier, A. (1968), Gigantisme cerebral de l'enfant dosage de l'hormone de croissance dans le plasma. Archives Francaises de Pediatrie, 25, 151-161.

Sotos, J. F., Dodge, P. R., Muirhead, D., Crawford, J. D., and Talbot, N. B. (1964). Cerebral gigantism in childhood: a syndrome of excessively rapid growth with acromegalic features and a nonprogressive neurologic disorder. New England fournal of Medicine, 271, 109-116.

Turner, E. K. and Sloan, L. E. G. (1967). Cerebral gigantism in childhood: a report of two cases and a review of the literature. Pediatrics, 40, 395-402. 